Research Article

\title{
Design and Application of Rapid Dewatering for Tailings Containing Sodium Silicate: Laboratory and Industrial Test Results
}

\author{
Guoquan Sun, ${ }^{1,2}$ Keping Zhou, ${ }^{1}$ Qian Kang $\mathbb{D}^{1,2,3}$ Daolin Wang, ${ }^{1}$ and Chongchun Xiao ${ }^{4}$ \\ ${ }^{1}$ School of Resources and Safety Engineering, Central South University, Changsha 410083, China \\ ${ }^{2}$ Sinosteel Maanshan General Institute of Mining Research Co., Ltd., Maanshan 243000, China \\ ${ }^{3}$ School of Resources \& Environment and Safety Engineering, University of South China, Hengyang 421001, China \\ ${ }^{4}$ Feny Co., Ltd., Changsha 410083, China
}

Correspondence should be addressed to Qian Kang; 79338186@qq.com

Received 19 October 2019; Accepted 31 January 2020; Published 28 February 2020

Guest Editor: Qi Jia

Copyright (C) 2020 Guoquan Sun et al. This is an open access article distributed under the Creative Commons Attribution License, which permits unrestricted use, distribution, and reproduction in any medium, provided the original work is properly cited.

Focusing on the tailings containing high sodium silicate (water glass), this study conducted laboratory experiments and semiindustrial tests of flocculation and sedimentation for rapid tailings dewatering. Various reagent combinations, lime and anionic flocculant (APAM) (L\&A), sulfuric acid and APAM (S\&A), and calcium chloride and APAM (C\&A), were tested. The results show that (i) all the three combinations presented a good effect in the laboratory experiments, and the relatively optimum dosages were L\&A of $2 \mathrm{~kg} / \mathrm{t} \& 30 \mathrm{~g} / \mathrm{t}$, S\&A of $2.6 \mathrm{~kg} / \mathrm{t} \& 20 \mathrm{~g} / \mathrm{t}$, and C\&A of $3 \mathrm{~kg} / \mathrm{t} \& 30 \mathrm{~g} / \mathrm{t}$. (ii) The overflow water of the L\&A group became turbid after 10 hours, and the $\mathrm{pH}$ increased to 14 . While, for the S\&A and C\&A groups, the solid content in overflow wastewater (SCOW) fluctuated over time but could be mostly controlled in $300 \mathrm{ppm}$. The $\mathrm{pH}$ declined from 7 to 4 with time in the S\&A group, and it was 7-8 in the C\&A group. (iv) Thus, a backfill system with dewatering technology based on the C\&A combination was designed. In the field application, the overflow water was recycled with the SCOW of less than $250 \mathrm{ppm}$ and the pH of 7.5, while the underflow concentration was greater than $70 \mathrm{wt} . \%$. The achievement provides a way to utilize the tailings containing sodium silicate effectively and environmentally, which will reduce the tailings dam on the Earth.

\section{Introduction}

Tailings are solid wastes generated from mineral processing. With the increasing demand of economic development for mineral resources, an astounding amount of tailings, approximately 1.2 billion tonnes per year in China, have been produced that have to be managed [1]. As a detrimental industrial waste, the improper disposal of tailings leads to some issues, such as floods, the proliferation of metal elements harmful to human health, the occupation of land, and the degradation of natural environment. In this case, the utilization of tailings for cemented tailings backfill (CTB) transported to underground has become widely used in many mines [2-4]. It has been also proven that CTB can not only reduce the cost of operation in a mine, but also provide an environmental way to treat this solid waste $[5,6]$. The quality and performance of cemented tailings backfill are affected by many factors [3, 6-14], including the mass fraction. In industrial application, it is necessary to raise the mass fraction of CTB so that the setting time of the backfill can be shortened and the strength of backfill can be improved significantly [15]. In this case, tailings dewatering has become a crucial issue affecting the application of backfill technology in a mine [16]. For the requirement of continuous backfill technology, rapid dewatering by flocculation and sedimentation (FS), agglomerating the fine particles with polymeric flocculants, has been widely used in backfill mines [17-20]. Despite the rapid dewatering function, FS also plays a role in purifying the solid content in overflow wastewater (SCOW) [21], which makes it possible to recycle the overflow water and protect the environment. 
Xianglushan Tungsten Mine (XTM), located in Jiangxi Province of China, is the second largest tungsten-producing mine in China, with a production capacity of 800,000 ton per year. A backfill system with a capacity of $80 \mathrm{~m}^{3} / \mathrm{h}$ was constructed in 2011. However, many muddy foams were produced (Figure 1) on the liquid surface even after adding different flocculants, leading to high SCOW. The overflow water contained high solid that could not be recycled and then transported to the river nearby, which contaminated the environment seriously. Thus, as a result, the backfill system was banned by the local environmental protection department. In this case, tailings dewatering has been a troublesome issue for XTM to realize the backfill technology and sustainable mining. Actually, this issue occurred in other tungsten mines nearby, such as Dajishan Tungsten Mine (Jiangxi Province of China) and Pangushan Tungsten Mine (Jiangxi Province of China), which have severely restricted sustainable enterprise development.

Through surveys, it was found that in the flotation plant in these mines, a large amount of dispersants and sodium silicate (water glass) [22] are added, as shown in Table 1. Sodium silicate is a dispersant widely selected in the traditionally fatty acid flotation process of tungsten minerals [23]. It also plays an important role in the flotation of scheelite and calcite [24]. As a dispersant, sodium silicate makes the solution a kind of colloid that has adhesion stress. Then, the fine particles in the tailings slurry will form a very stable colloidal dispersion to prevent the adsorption between particles and flocculants $[25,26]$, which should be the key issue affecting the effect of FS.

Setting time is a key parameter for sustainable tailing operations and thereby paste backfill production. Larger underground stopes need greater filing rates for paste backfill production. Thus, chemicals that accelerate the settlement time of tailings must be chosen for nonstop backfilling. Previous researches presented effective schemes to treat mineral processing wastewater containing sodium silicate. Among them, lime is the most widely used for purifying mineral processing wastewater [27]. Additionally, as substitutes for lime, the usage of industrial by-products and cement kiln dust (CKD) was tested to treat the wastewater [28]. The chemical equation is as follows: $\mathrm{Na}_{2} \mathrm{SiO}_{3}+\mathrm{Ca}(\mathrm{OH})_{2}=\mathrm{CaSiO} 3 \downarrow+2 \mathrm{NaOH}$. In addition, the strong acid was also selected as an agent in the treatment of mine drainage and achieved a good effect [29]. The chemical equation is as follows: $\mathrm{Na}_{2} \mathrm{SiO}_{3}+2 \mathrm{H}^{+} \longrightarrow 2 \mathrm{Na}^{+}+\mathrm{H}_{2} \mathrm{SiO}_{3} \downarrow$. However, they are both used in a concrete container with a large diameter for a static process, and the requirement of underflow concentration is about 38-45 wt.\%, lower than that of $65-75$ wt.\% in CTB. Also, the setting time used was more than 8 hours, which could not satisfy the continuous operation of CTB. Anyway, the achievements above guide the research about treatment of sodium silicate in this paper. Furthermore, inspired by the previous outcomes, another strong electrolyte, $\mathrm{CaCl}_{2}$, was taken consideration to treat the sodium silicate in this study.

Therefore, in this paper, focusing on the tailings slurry containing high sodium silicate in XTM, some laboratory experiments and semi-industrial tests were conducted. Lime, sulfuric acid, and calcium chloride were selected to remove the sodium silicate before FS with polymeric flocculant. Through evaluating the indexes, such as the qualitative settling velocity, the handling capacity, SCOW, and the underflow concentration, a feasible and reliable scheme for tailings dewatering was proposed. Finally, the industrial application of this craft has been presented and evaluated.

\section{Materials and Methods}

\subsection{Materials}

2.1.1. Tailings Slurry. In the laboratory experiments, the tailings slurry used were received from the tailings discharge outlet in XTM. The tailings slurry samples with concentrations of approximately $20 \mathrm{wt} . \%$ were collected every half an hour for 8 hours when the ore-dressing plant was in operation. The properties (especially the sodium silicate content) of the original tailings slurry could thus be maintained. In semi-industrial tests, the tailings slurry was directly pumped into a mixer located at the semi-industrial test site through a pipeline.

The particle size distribution and other physical properties of tailings are presented in Figure 2 and Table 2. As described in Figure 2, the particles smaller than $19 \mu \mathrm{m} \mathrm{ac}-$ count for $30.40 \mathrm{wt}$ \%, which makes it impossible to realize tailing dewatering by self-gravity, even if ignoring the sodium silicate $[30,31]$.

\subsubsection{Reagents for the Treatment of Sodium Silicate (RTS).} Considering the convenience and cost of obtaining the materials, lime, sulfuric acid, and calcium chloride were selected to treat the sodium silicate in this study. Lime was provided by XTM itself. The sulfuric acid and calcium chloride were manufactured by YiCheng Co., Ltd., Hunan Province of China, and their prices are $50 \mathrm{Yuan} / \mathrm{L}$ (98\%) and 3000 Yuan/t, separately.

2.1.3. Polymeric Flocculant. Generally, APAM (anionic polyacrylamide) is a commonly used flocculant for tailings dewatering [32-34]. Then, after some trial tests comparing the effect of different flocculants, an APAM with a molecular weight of 18 million (manufactured by BASF SE, Germany) was selected in this paper. The price of APAM is $7000 \mathrm{Yuan} / \mathrm{t}$.

2.2. Experimental Methods. The experiments in this study consisted of a laboratory experiment and a semi-industrial test. The laboratory experiment was a static test, and the purpose was to determine the optimum dosages of different reagents through observation of the qualitative settling velocity. Then, the semi-industrial test was aimed at verifying the effect by detecting various crucial indexes.

2.2.1. Laboratory Experiment. The laboratory experiment was divided into the following three groups: (i) adding the lime and APAM (L\&A); (ii) adding the sulfuric acid and APAM (S\&A); and (iii), adding the calcium chloride and 


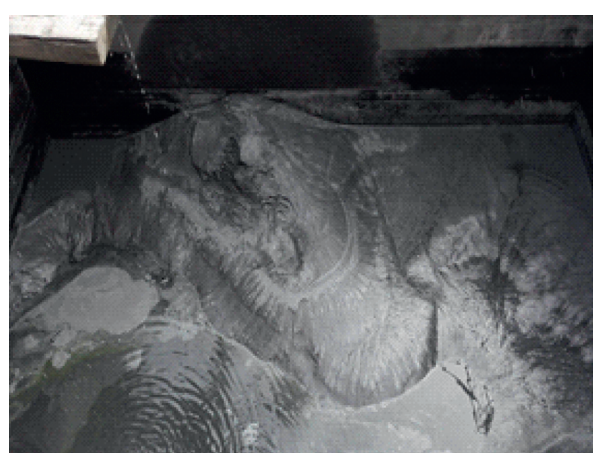

(a)

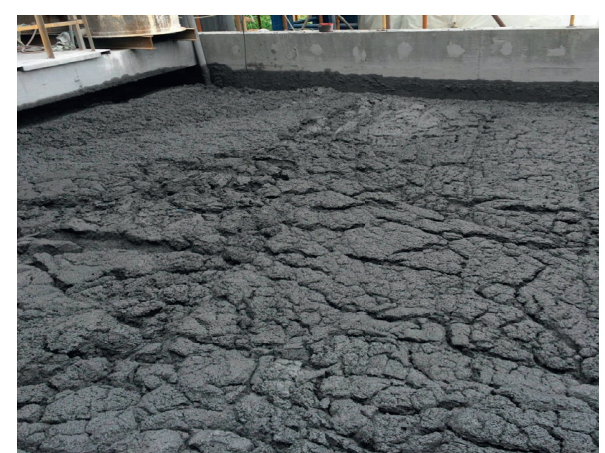

(b)

FIgUre 1: Muddy foams on the liquid surface in XTM: (a) initial operation; (b) after 7 days.

TABLE 1: Sodium silicate added during the mineral process (kg per ton of original ore).

\begin{tabular}{lccc}
\hline Mines & $\begin{array}{c}\text { Xianglushan } \\
\text { tungsten mine }\end{array}$ & $\begin{array}{c}\text { Dajishan } \\
\text { tungsten mine }\end{array}$ & $\begin{array}{c}\text { Pangushan } \\
\text { tungsten mine }\end{array}$ \\
\hline Sodium silicate & $10-15$ & $4-6$ & $8-12$ \\
\hline
\end{tabular}

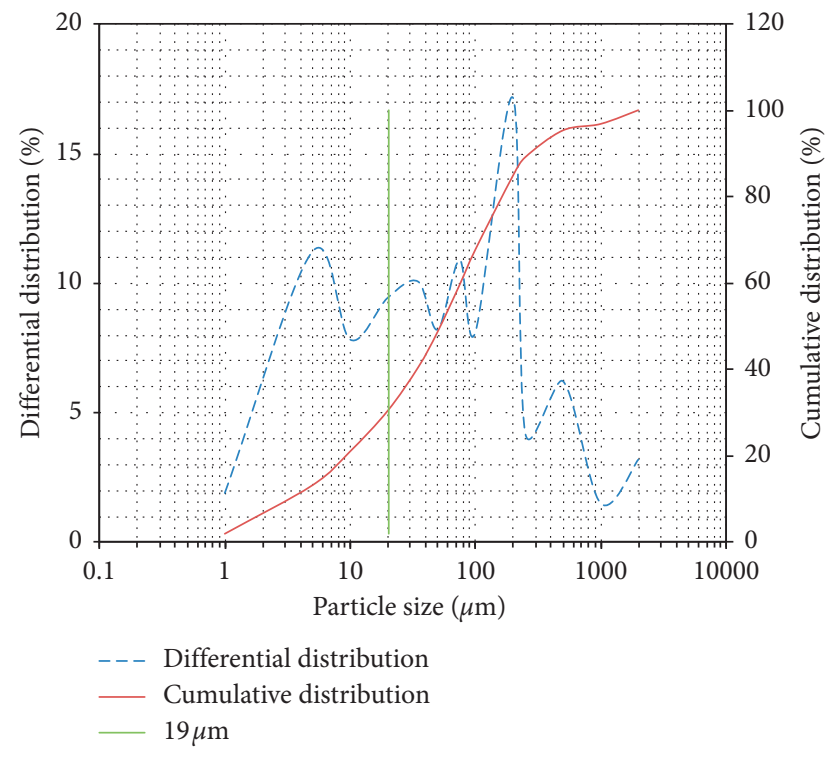

Figure 2: Particle size distribution of tailings.

APAM (C\&A). The experimental method was conducted as follows:

(1) Preparation of reagents. A 10 wt.\% sulfuric acid solution was prepared in $2000 \mathrm{~mL}$ beakers. The lime and calcium chloride were prepared and measured with an electronic scale when used.

(2) Preparation of APAM. An APAM solution of 1.0 wt. $\%$ o was prepared in $1000 \mathrm{~mL}$ measuring cylinders. Considering polyacrylamide dissolves slowly, this step was completed 0.5-1 hour ahead of the experiment.

(3) Preparation of tailing slurry. The tailings slurry selected from the ore-processing plant was mixed evenly under a lifting mixer (JJ-100W, Hongda, Hebei Province of China).

(4) Experimental progress. The tailings slurry in the lifting mixer was pumped into a $1000 \mathrm{~mL}$ measuring cylinder by a small peristaltic pump (BT-300EA, manufactured by Hengjie, Shanghai of China). Simultaneously, the designed RTS was added. Then, a stirrer mixed the mixture in the cylinder with a rubber mesh for $30 \mathrm{~s}$ after adding the APAM solution. Finally, the cylinder was placed on a table to monitor the height of the solid-liquid interface. The designed dosage of the reagents and flocculants can be observed in the results.

\subsubsection{SEMI-Industrial Test}

(1) Process of Semi-Industrial Test. A system of tailings dewatering based on a designed semi-industrial apparatus was constructed, as shown in Figure 3. As indicated in the figure, the tailings slurry from the ore-dressing plant of XTM was transported to a buffered mixer (XB-1000, Shicheng, Jiangxi) by self-flowing. The RTS was transported to the mixer at the same time. The RTS and APAM solutions were prepared in two flocculant preparation systems in the reagent preparation room. Then, the treated tailings slurry and APAM solution were concurrently pumped to a feed tank located at the top of a deep-cone thickener (diameter $\times$ height $=1000 \mathrm{~mm} \times 8000 \mathrm{~mm}$, manufactured by Feny Co. Ltd., Hunan Province of China) by a hose pump (KP 300, Jieheng, Chongqing of China).

(2) Indexes Detection. SCOW and $\mathrm{pH}$. The tailings dewatering is a long-term and dynamic process in the industrial applications. Therefore, the variation of SCOW and $\mathrm{pH}$ with time should be considered. SCOW was detected through a vacuum filter (2BE, Zhongxing Co., Ltd., Beijing of China), as shown in Figure 4(a). According to the water recycling requirement studied in XTM before, the SCOW must be controlled to be less than 300 ppm [35]. Furthermore, the pH was detected with $\mathrm{pH}$ test pen.

Handling capacity. It is necessary to determine the best handling capacity first, which is a key parameter affecting the 
TABLE 2: Physical properties of tailings in XTM.

\begin{tabular}{lcccccccc}
\hline$D<19(\mu \mathrm{m})$ & $D_{10}(\mu \mathrm{m})$ & $D_{30}(\mu \mathrm{m})$ & $D_{50}(\mu \mathrm{m})$ & $D_{60}(\mu \mathrm{m})$ & $C_{\mathrm{u}}$ & $C_{\mathrm{c}}$ & $\mathrm{G}\left(\mathrm{g} / \mathrm{m}^{3}\right)$ & $\mathrm{pH}$ \\
\hline 30.40 & 3.89 & 19.58 & 53.32 & 46.12 & 11.86 & 2.14 & 2.99 & 9.0 \\
\hline
\end{tabular}

Note: $\mathrm{G}$ depicts the specific gravity. $C_{\mathrm{u}}$ depicts uniformity coefficient. $C_{\mathrm{c}}$ depicts curvature coefficient.

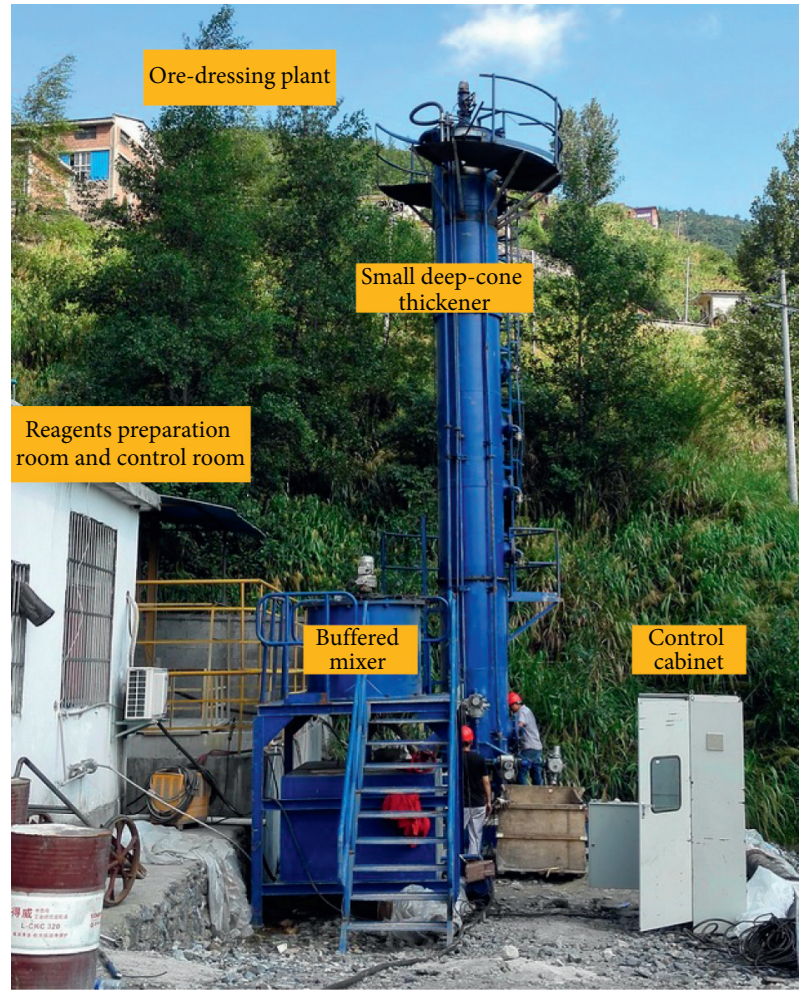

FIgURE 3: Layout of the semi-industrial test.

SCOW and the design of the deep-cone thickener in industrial applications [17]. The handling capacity can be calculated through the feeding rate of tailings slurry as follows:

$$
T_{h}=\frac{m_{t}}{A}=\frac{\rho Q C}{\pi r^{2}}
$$

where $T_{h}$ denotes the $\mathrm{HC}, \mathrm{t} \cdot \mathrm{m}^{-2} \cdot \mathrm{h}^{-1} ; m_{\mathrm{t}}$ is the tailings quality in a hour, $\mathrm{t} / \mathrm{h} ; \rho$ is the density of the tailings slurry, $1.28 \mathrm{t} / \mathrm{m}^{3}$; $Q$ denotes the feeding rate of the tailings slurry, $\mathrm{m}^{3} / \mathrm{h} ; C$ is the mass fraction of the tailings slurry, wt.\%; and $r$ depicts the radius of the deep-cone thickener, $0.5 \mathrm{~m}$, so the area, $A$, is $0.785 \mathrm{~m}^{2}$.

Underflow concentration. The underflow was collected and placed in a given container with certain weight and volume, as shown in Figure 4(b). After drying until the weight was stable, the weight of dry tailings was obtained. Then, the underflow concentration could be determined.

\section{Results and Discussion}

\subsection{Static Dewatering in Laboratory Experiments}

3.1.1. Effect of L\&A. Figure 5 describes the height variation of the solid-liquid interface with time for different dosage combinations with lime and APAM. It can be observed from this figure that both the lime and APAM have an optimum dosage that makes the solid-liquid interface settle the fastest. As depicted in Figure 5(a), when the APAM was kept at $30 \mathrm{~g} /$ $t$, the FS shows the best effect when the additional amount of lime was $2 \mathrm{~kg} / \mathrm{t}$. Additionally, with the increase in lime consumption, the settling velocity decreased. This is because that the solubility of $\mathrm{Ca}(\mathrm{OH})_{2}$ is not significant, and the excessive $\mathrm{Ca}(\mathrm{OH})_{2}$ is suspended in the liquid, likely affecting the effect of FS.

In addition, when the lime was kept at $2 \mathrm{~kg} / \mathrm{t}$, an APAM addition of $30 \mathrm{~g} / \mathrm{t}$ made the effect of the settling velocity of the solid-liquid interface the fastest, as shown in Figure 5(b). Previous publications have determined that the dosage of flocculants has a best value for a given material $[36,37]$.

The optimum combination of L\&A is lime of $2 \mathrm{~kg} / \mathrm{t}$ and APAM of $30 \mathrm{~g} / \mathrm{t}$. This combination was not extremely accurate but rather used as a reference for industrial application. Figure 6 presents photographs of the FS effect. Experiences indicate that excessive dosages (more than $30 \mathrm{~g} /$ t) of admixtures can create some problems: blockages and abrasiveness when there is a distance between thickener and backfill plant. Thus, selection of proper admixtures is vital for sustainable operations.

3.1.2. Effect of SeAA. Similar to the lime, sulfuric acid is also used as a reagent to treat the sodium silicate in the tailings slurry. The chemical reaction is as follows: $\mathrm{Na}_{2} \mathrm{SiO}_{3}+\mathrm{H}_{2} \mathrm{SO}_{4}=\mathrm{Na}_{2} \mathrm{SO}_{4}+\mathrm{H}_{2} \mathrm{SiO}_{3} \downarrow$.

The relative molecular masses of $\mathrm{Ca}(\mathrm{OH})_{2}$ and $\mathrm{H}_{2} \mathrm{SO}_{4}$ are 74 and 98, respectively; thus, according to the optimum dosage of lime at $2 \mathrm{~kg} / \mathrm{t}$, the sulfuric acid consumption in this study was kept as $2 \mathrm{~kg} / \mathrm{t} \times(98 / 74) \approx 2.6 \mathrm{~kg} / \mathrm{t}$.

Figure 7 (a) depicts the height variation of the solidliquid interface with time when the addition of sulfuric acid was $2.6 \mathrm{~kg} / \mathrm{t}$ and the APAM changed from $10 \mathrm{~g} / \mathrm{t}$ to $40 \mathrm{~g} / \mathrm{t}$. This figure indicates that when the dosage of APAM is $20 \mathrm{~g} / \mathrm{t}$, the settling velocity presents the best effect. Then, with the increase of APAM, the settling trend variation is not obvious and even lower. The best combination of S\&A is sulfuric acid of $2.6 \mathrm{~kg} / \mathrm{t}$ and APAM of $20 \mathrm{~g} / \mathrm{t}$, approximately. In this case, the experimental photograph is shown in Figure 7(b).

3.1.3. Effect of C\&A. Likewise, the relative molecular mass of $\mathrm{CaCl}_{2}$ is 110 ; thus, the calcium chloride consumption was $3 \mathrm{~kg} / \mathrm{t}$. Additionally, in this case, Figure 8(a) shows the height variation of the solid-liquid interface with time when the addition of calcium chloride was $3 \mathrm{~kg} / \mathrm{t}$ and the APAM changed from $10 \mathrm{~g} / \mathrm{t}$ to $40 \mathrm{~g} / \mathrm{t}$. It can be concluded that the best combination is approximately calcium chloride of $3 \mathrm{~kg} / \mathrm{t}$ and APAM of $30 \mathrm{~g} / \mathrm{t}$. Figure 8 (b) presents the effect at this combination. 


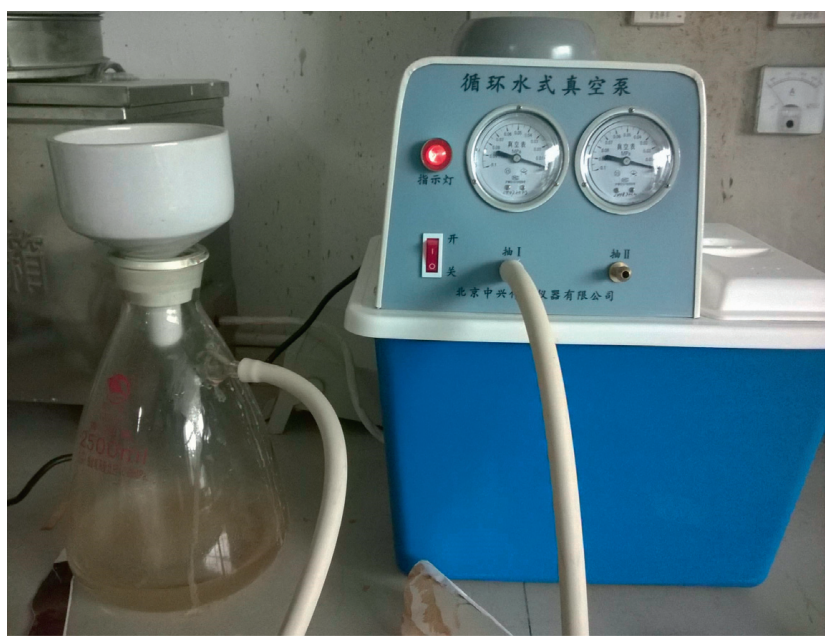

(a)

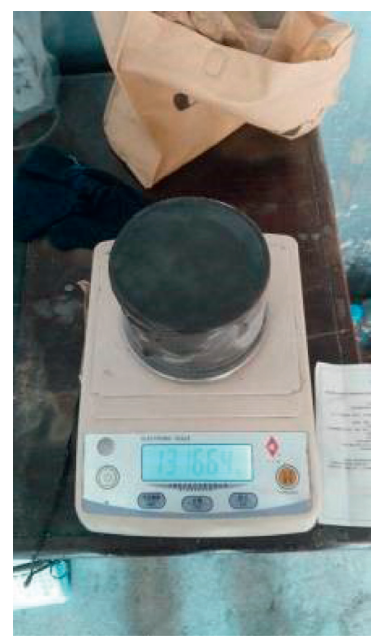

(b)

FIGURE 4: Detection of (a) SCOW and (b) underflow concentration.

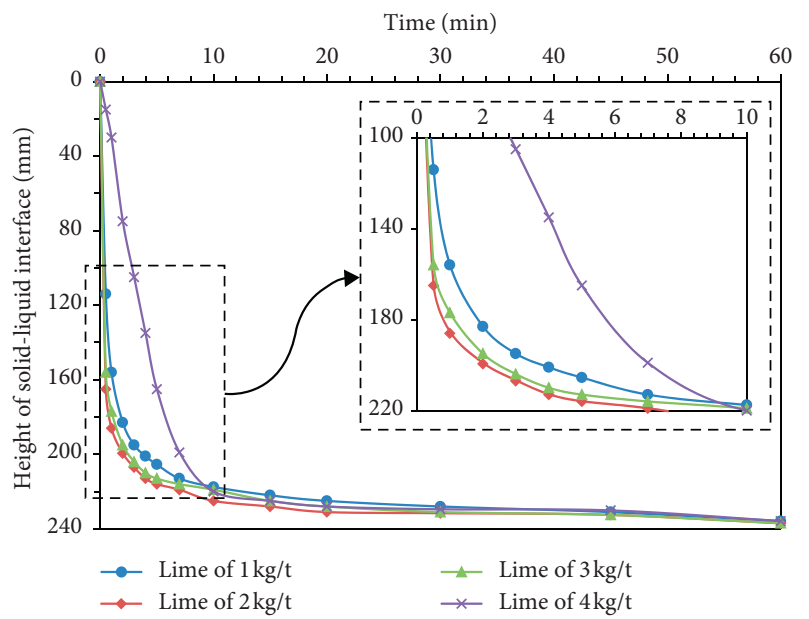

(a)

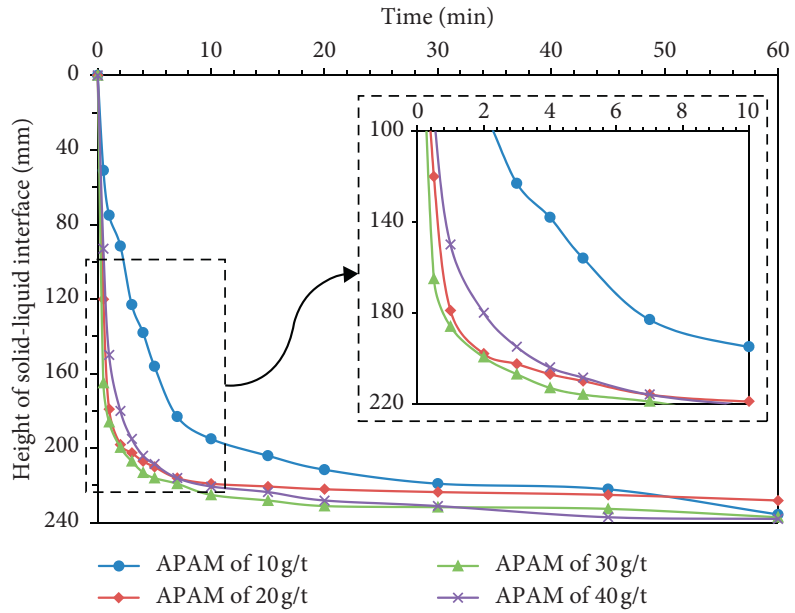

(b)

FIGURE 5: Height variation of the solid-liquid interface with time (a) when the dosage of APAM was $30 \mathrm{~g} / \mathrm{t}$ and the addition of lime changed from $1 \mathrm{~kg} / \mathrm{t}$ to $4 \mathrm{~kg} / \mathrm{t}$; (b) when the addition of lime was $2 \mathrm{~kg} / \mathrm{t}$ and the APAM changed from $10 \mathrm{~g} / \mathrm{t}$ to $40 \mathrm{~g} / \mathrm{t}$.

\subsection{Dynamic Dewatering in the Semi-Industrial Test}

3.2.1. Best Handling Capacity (BHC). The reagent dosage was kept consistent with the results of the laboratory experiments, while the feeding rate of tailings slurry was changed from $1.6 \mathrm{~m}^{3} / \mathrm{h}$ to $2.6 \mathrm{~m}^{3} / \mathrm{h}$ to detect the SCOW variation. That is, the handling capacity changed from $0.39 \mathrm{t} \cdot \mathrm{m}^{-2} \cdot \mathrm{h}^{-1}$ to $0.64 \mathrm{t} \mathrm{m}^{-2} \cdot \mathrm{h}^{-1}$. This process lasted for only one hour. Figure 9 describes the variation of SCOW with varying handling capacity. This figure indicates that the SCOW increases with the handling capacity. According to the water recycling requirements, the SCOW must be controlled to be less than $300 \mathrm{ppm}$. In this case, it was concluded that the BHC values of L\&A, S\&A, and C\&A groups were $0.54 \mathrm{t} \cdot \mathrm{m}^{-2} \cdot \mathrm{h}^{-1}, \quad 0.49 \mathrm{t} \cdot \mathrm{m}^{-2} \cdot \mathrm{h}^{-1}$, and $0.59 \mathrm{t} \cdot \mathrm{m}^{-2} \cdot \mathrm{h}^{-1}$, respectively. It is obvious that the S\&A group presented the worst handling capacity in FS. As we know, unlike $\mathrm{CaSiO}_{3}, \mathrm{H}_{2} \mathrm{SiO}_{3}$ is a flocculant precipitate in the water, which may more or less affect the adsorption between tailings and flocculants $[38,39]$.

3.2.2. Variation of SCOW and $\mathrm{pH}$ with Time. Figure 10 comprehensively depicts the change of SCOW and $\mathrm{pH}$ with time under the determined reagents dosages and $\mathrm{BHC}$. Figure 11 presents the FS effect of different combinations on the liquid surface after 10 hours. Analysing these figures, the following conclusions are suggested:

(1) For the L\&A group, the SCOW increased gradually with time. After 10 hours of continuous operation, the detected SCOW increased beyond the criterion higher than $300 \mathrm{ppm}$. And, many muddy foams gathered on the liquid surface at this time, as Figure 11(a) shows. In addition, the $\mathrm{pH}$ varied from 11 to 14 , which meant that the 


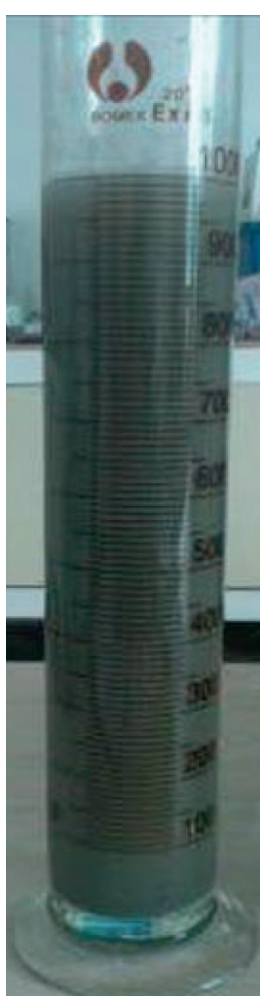

(a)

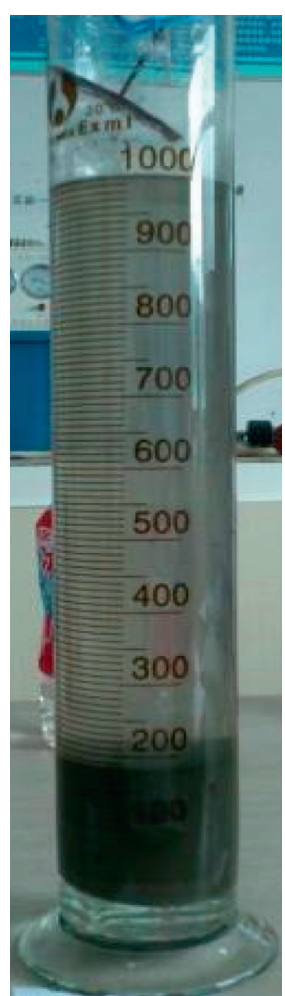

(b)

Figure 6: Photographs of (a) sample without adding lime and (b) sample with lime of $2 \mathrm{~kg} / \mathrm{t}$ and APAM of $30 \mathrm{~g} / \mathrm{t}$.

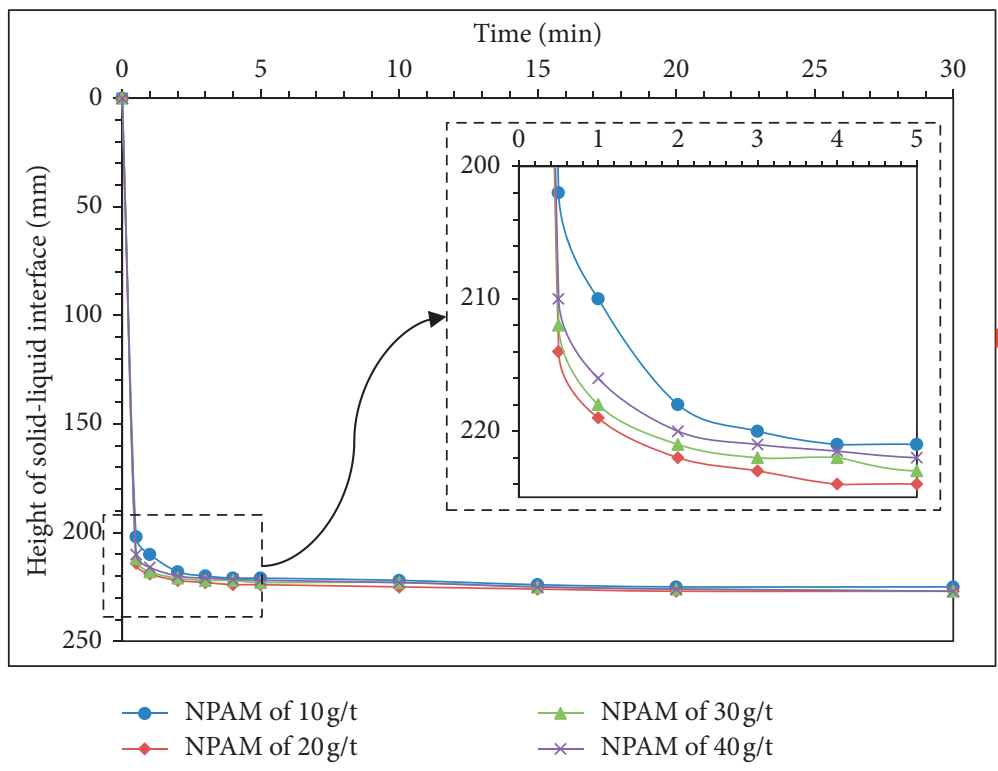

(a)

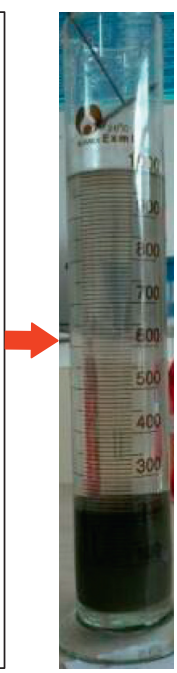

(b)

Figure 7: (a) Height variation of the solid-liquid interface with time when the addition of sulfuric acid was $2.6 \mathrm{~kg} / \mathrm{t}$ and the APAM changed from $10 \mathrm{~g} / \mathrm{t}$ to $40 \mathrm{~g} / \mathrm{t}$; (b) experimental effect at sulfuric acid of $2.6 \mathrm{~kg} / \mathrm{t}$ and APAM of $20 \mathrm{~g} / \mathrm{t}$.

overflow water was strongly alkaline because $\mathrm{OH}$ was produced after adding lime. In this alkaline environment, some of the remaining foaming agent and foam stabilizer used for flotation would produce stable foams [40]. These foams adsorbed some tailings particles to affect the FS effect and increase the SCOW. Stable muddy foams would also affect the thickener underflow and thereby the behaviour of cemented backfill produced from these tailings 


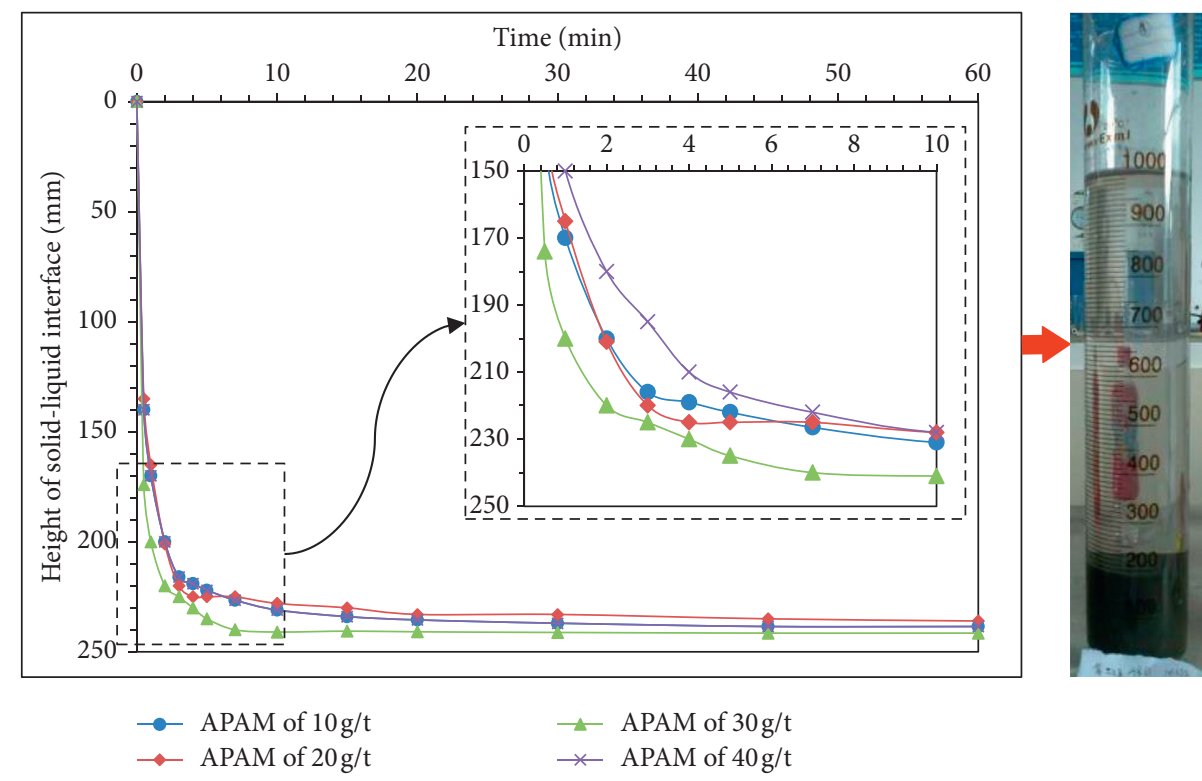

(a)

(b)

FIGURE 8: (a) Height variation of solid-liquid interface with time when the addition of calcium chloride was $3 \mathrm{~kg} / \mathrm{t}$ and the APAM changed from $10 \mathrm{~g} / \mathrm{t}$ to $40 \mathrm{~g} / \mathrm{t}$; (b) the effect of FS at calcium chloride of $3 \mathrm{~kg} / \mathrm{t}$ and APAM of $30 \mathrm{~g} / \mathrm{t}$.

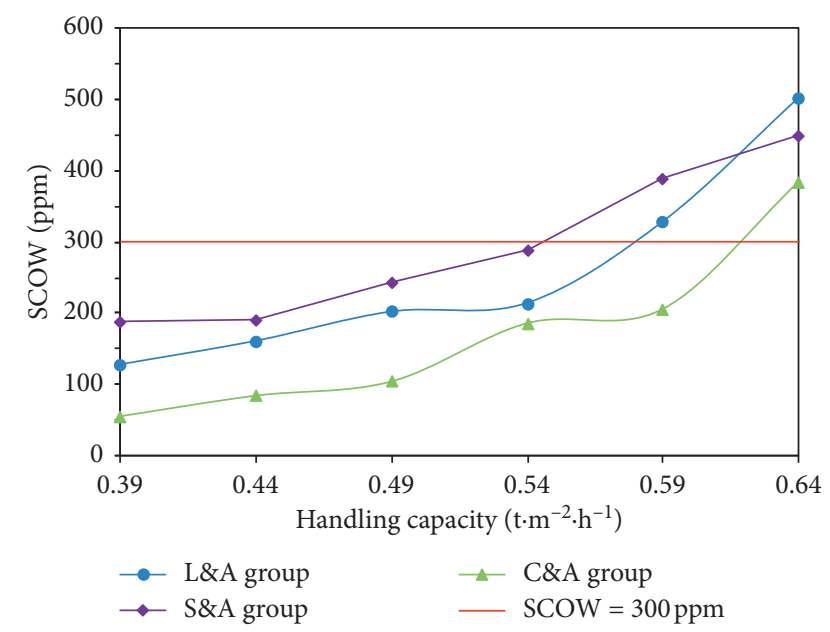

FIGURE 9: Variation of SCOW with varying handling capacity under the different reagent combinations.

(2) For the S\&A and C\&A groups, the SCOW fluctuated over time but was mostly controlled at $300 \mathrm{ppm}$. Furthermore, the $\mathrm{pH}$ declined from 7 to 4 with time in the S\&A group, while the $\mathrm{pH}$ remained at 7-8 in the C\&A group. It can be observed from Figures 11(b) and 11 (c) that the overflow in these groups showed high clarity. However, the low $\mathrm{pH}$ in the S\&A group required anticorrosion treatment for devices and a neutralization system for $\mathrm{pH}$. These additions will increase both the initial investment and operating cost.

3.2.3. Variation of Underflow Concentration with Time. Figure 12 describes the underflow concentration variation for different combinations with time. It can be observed that

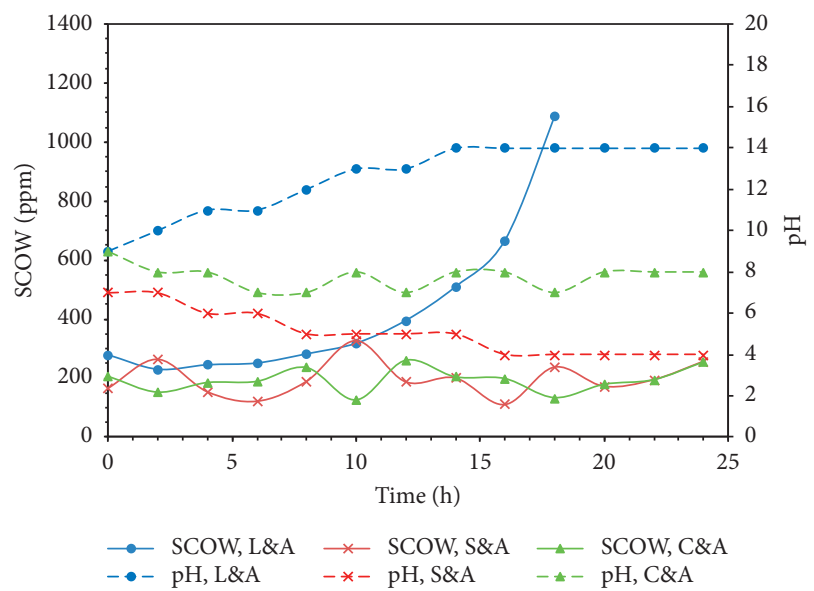

FIGURE 10: Variation of SCOW of different combinations with varying time.

the underflow concentration increased with time and remained mostly higher than 70 wt.\% after 10 or 12 hours for the S\&A group and C\&A group, except for a trend of decline in the C\&A group after 12 hours. Actually, the final concentration of tailings mainly depends on its own characteristics and the parameters of the deep-cone thickener $[41,42]$ regarding waste of time. However, in the continuous CTB backfill, the rapid dewatering is required to ensure the high underflow concentration in a limited time. As studied above, the effect became worse after 10 hours, which then affects the settling velocity and, as a result, the underflow concentration dropped.

3.2.4. Selection of Dewatering Scheme. Table 3 compares the effect of different combinations on FS. It is obvious that the cost of the C\&A group is the most expensive. However, the 


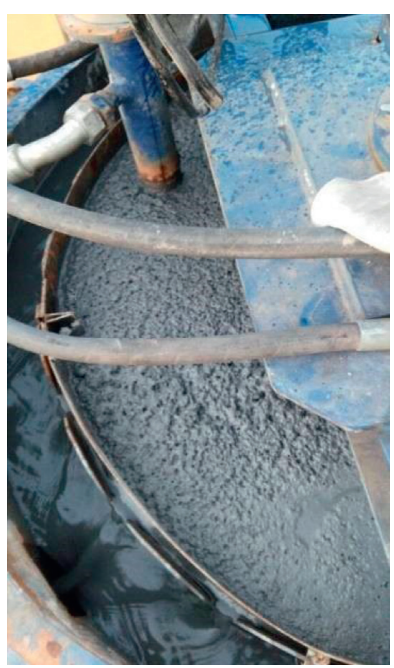

(a)

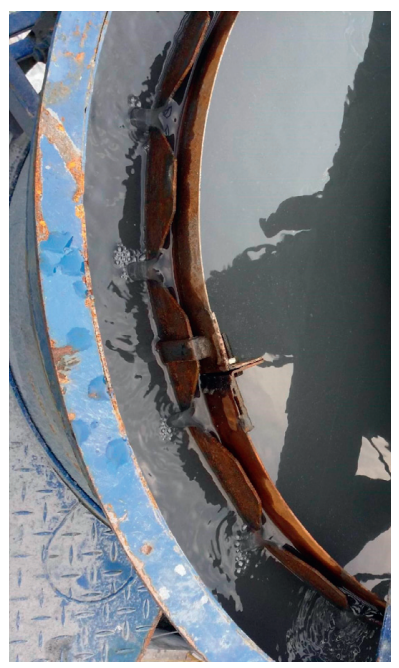

(b)

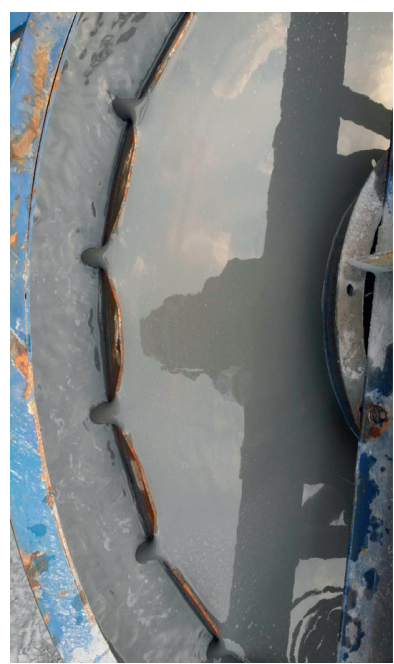

(c)

FIGURE 11: FS effect of different combinations on the liquid surface in the small deep-cone thickener after operating for 10 hours: (a) L\&A group, (b) S\&A group, and (c) C\&A group.

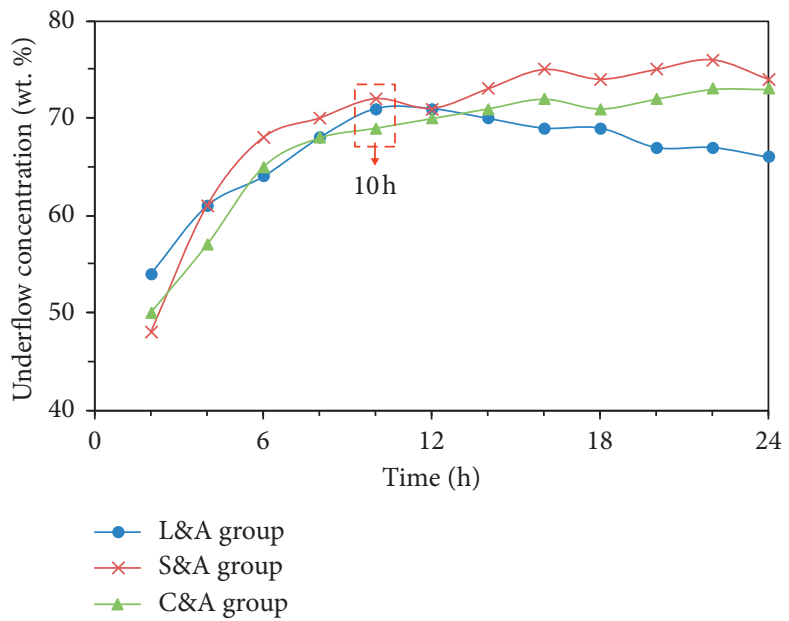

FIgURE 12: Variation of underflow concentration of different combinations with time.

other combinations require equipment to remove the foams or neutralize the $\mathrm{pH}$ of the overflow water. Specially, the acid environment in the S\&A group is potentially harmful to people and requires devices to be treated for corrosion. These additional crafts will increase the cost more than the higher dosage cost in the C\&A group. Complex craft leads to increased difficulty in operation and control. In addition, the BSU of the C\&A group is maximal, which will reduce the diameter of the deep-cone thickener. Synthetically, the C\&A group was selected in XTM.

3.3. Industrial Evaluation. Figure 13 depicts the backfill setup with new dewatering technology based on the results of this research. The tailings with the concentration of $20 \mathrm{wt} . \%$ from ore-dressing plant are pumped to a laminar mixer (CLHYQ-8, manufactured by Huaxing, Pingdingshan of China) with the calcium chloride solution. Then, the treated tailings slurry is transported to a deep-cone thickener (NGT18, manufactured by Feny, Hunan of China) while the APAM solution is added. Next, a shear pump (60NJ-485, manufactured by Tianmen, Hubei of China) is used to pump the tailings with a concentration of 70 wt.\% to a mixer (XB-2000, Shicheng, Jiangxi). The cemented paste will be formed in combination with the tailings, cement, and water (if needed). Finally, the paste is pumped to a stope underground, and the overflow water is stored in a recycling reservoir.

Figure 14presents the overflow water and underflow concentration in the field application. The figure indicates that the overflow water showed good clarity. Actually, the SCOW detected in the field could be controlled at approximately $250 \mathrm{ppm}$, while the underflow concentration maintained a concentration higher than $70 \mathrm{wt} . \%$ and often reached a highest value of 73 wt.\%. In addition, the overflow water has been recycled in the ore-processing craft successfully, which shows an economic and environmental effect. 
TABle 3: Comparison of different dewatering schemes.

\begin{tabular}{|c|c|c|c|c|}
\hline No & Items & L\&A & S\&A & C\&A \\
\hline 1 & Dosage of reagents & & & \\
\hline 1.1 & Lime $(\mathrm{kg} / \mathrm{t})$ & 2 & & \\
\hline 1.2 & $\mathrm{H}_{2} \mathrm{SO}_{4}(\mathrm{~kg} / \mathrm{t})$ & & 2.6 & \\
\hline 1.3 & $\mathrm{CaCl}_{2}(\mathrm{~kg} / \mathrm{t})$ & & & 3 \\
\hline 1.4 & $\operatorname{APAM}(\mathrm{g} / \mathrm{t})$ & 30 & & $30 \mathrm{~g} / \mathrm{t}$ \\
\hline 1.5 & NAPAM $(g / t)$ & & 20 & \\
\hline 2 & Reagent cost (US \$/t) & 0.27 & 0.31 & 0.39 \\
\hline 2 & BHC $\left(\mathrm{t} /\left(\mathrm{m}^{2} \cdot \mathrm{h}\right)\right)$ & 0.54 & 0.49 & 0.59 \\
\hline 3 & SCOW (ppm) in 24 hours & $>300$, after 10 hours & $<300$ & $<300$ \\
\hline 4 & $\mathrm{pH}$ after 24 hours of operation & 14 & 4 & 8 \\
\hline 5 & Underflow concentration & $<70$ wt. $\%$ after 12 hours & $>70$ wt. $\%$ & $>70$ wt. $\%$ \\
\hline 6 & Additional devices & & & \\
\hline 6.1 & Defoaming device & 2 (one for spare) & & \\
\hline 6.2 & Neutralization system for $\mathrm{pH}$ & 2 (one for spare) & 2 (one for spare) & \\
\hline 6.3 & Anticorrosion treatment & & 1 & \\
\hline
\end{tabular}

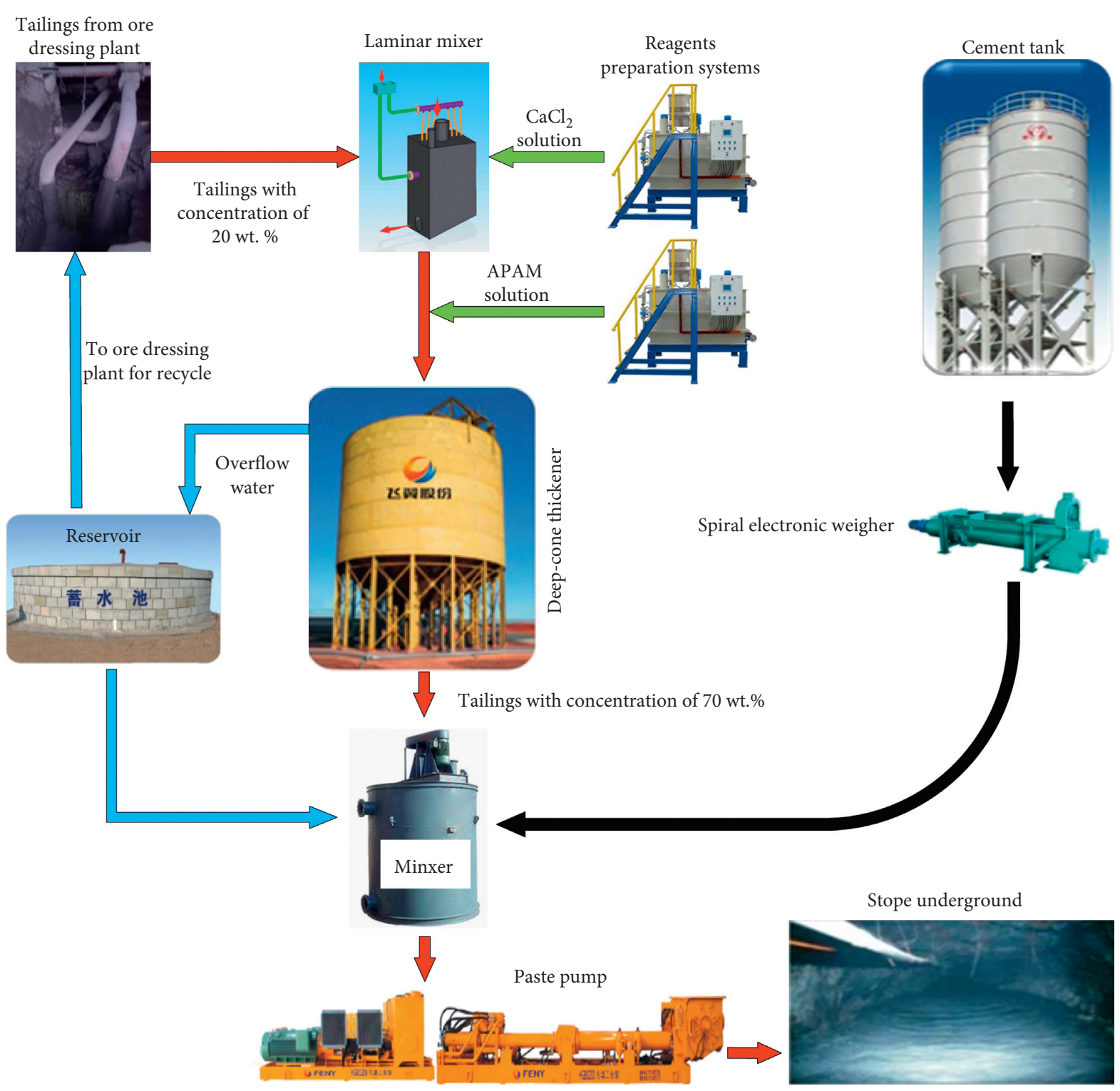

FIgURE 13: Backfill setup with new FS technology in XTM. 


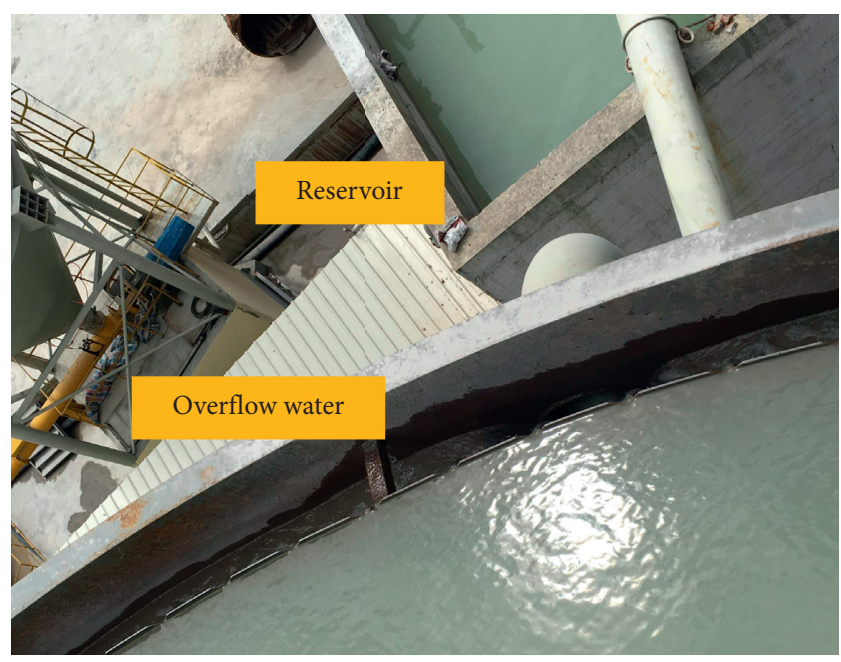

(a)

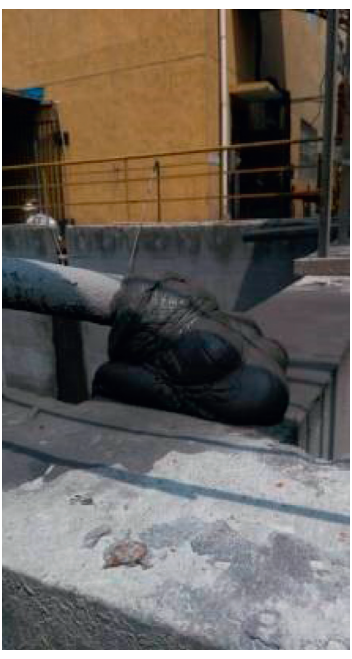

(b)

Figure 14: Overflow water (a) and underflow tailings (b) in the field application.

\section{Conclusions}

This study conducted laboratory experiments and semiindustrial tests for dewatering the tailings containing high sodium silicate (water glass). In addition, the industrial application was also evaluated. Based on the results, the following conclusions are obtained.

(1) Lime, sulfuric acid, and calcium chloride showed a good FS effect in the laboratory experiments when combined with APAM.

(2) The selected BHC values of the L\&A, S\&A, and C\&A groups were $0.54 \mathrm{t} \cdot \mathrm{m}^{-2} \cdot \mathrm{h}^{-1}, \quad 0.49 \mathrm{t} \cdot \mathrm{m}^{-2} \cdot \mathrm{h}^{-1}$, and $0.59 \mathrm{t} \cdot \mathrm{m}^{-2} \cdot \mathrm{h}^{-1}$, respectively.

(3) In the semi-industrial tests, the overflow water of the L\&A group became turbid after 10 hours, and the $\mathrm{pH}$ increased to 14 . For the S\&A and C\&A groups, the SCOW fluctuated over time but could be mostly controlled at $300 \mathrm{ppm}$. In addition, the $\mathrm{pH}$ declined from 7 to 4 with time in the S\&A group, while the $\mathrm{pH}$ was 7-8 in the C\&A group.

(4) The C\&A group (calcium chloride and APAM) was selected in the field. The backfill craft with new FS technology based on the result was designed and operated. It presented a good effect with an SCOW of less than $250 \mathrm{ppm}$ and an underflow concentration of greater than $70 \mathrm{wt} . \%$. The achievement of this paper provides a way to utilize the tailings effectively and environmentally, which will also reduce the tailings dam on the Earth. It needs to be note that, however, the FS with two steps is too complicated in engineering application. A new technology with one reagent should be thus studied in the future.

\section{Data Availability}

The photograph data used to support the findings of this study are all included within the article.

\section{Conflicts of Interest}

The authors declare that there are no conflicts of interest regarding the publication of this paper.

\section{Acknowledgments}

This study was financially supported by the State Key Laboratory of Safety and Health for Metal Mines (2017-JSKSSYS03 and 2019-JSKSSYS-02) and the Research Project of Education Department of Hunan Province(17C1375).

\section{References}

[1] X. Song, J. B. Pettersen, K. B. Pedersen, and S. Røberg, "Comparative life cycle assessment of tailings management and energy scenarios for a copper ore mine: a case study in northern Norway," Journal of Cleaner Production, vol. 164, 2017.

[2] A. Wu, Y. Wang, H. Wang, S. Yin, and X. Miao, "Coupled effects of cement type and water quality on the properties of cemented paste backfill," International Journal of Mineral Processing, vol. 143, pp. 65-71, 2015.

[3] Y. He, Q. Chen, C. Qi, Q. Zhang, and C. Xiao, "Lithium slag and fly ash-based binder for cemented fine tailings backfill," Journal of Environmental Management, vol. 248, p. 109282, 2019.

[4] Q.-S. Chen, Q.-L. Zhang, A. Fourie, X. Chen, and C.-C. Qi, "Experimental investigation on the strength characteristics of cement paste backfill in a similar stope model and its mechanism," Construction and Building Materials, vol. 154, pp. 34-43, 2017.

[5] Q. Chen, Q. Zhang, A. Fourie, and C. Xin, "Utilization of phosphogypsum and phosphate tailings for cemented paste backfill," Journal of Environmental Management, vol. 201, pp. 19-27, 2017.

[6] Y. Feng, Q. Yang, Q. S. Chen et al., "Characterization and evaluation of the pozzolanic activity of granulated copper slag modified with CaO," Journal of Cleaner Production, vol. 232, pp. 1112-1120, 2019. 
[7] S. Cao, E. Yilmaz, and W. Song, "Evaluation of viscosity, strength and microstructural properties of cemented tailings backfill," Minerals, vol. 8, no. 8, p. 352, 2018.

[8] S. Cao, E. Yilmaz, and W. Song, "Dynamic response of cement-tailings matrix composites under SHPB compression load," Construction and Building Materials, vol. 186, pp. 892-903, 2018.

[9] S. Cao, E. Yilmaz, G. Xue, and W. Song, "Assessment of acoustic emission and triaxial mechanical properties of rock-cemented tailings matrix composites," Advances in Materials Science and Engineering, vol. 2019, Article ID 6742392, 12 pages, 2019.

[10] H. Jiang, H. Yi, E. Yilmaz, S. Liu, and J. Qiu, "Ultrasonic evaluation of strength properties of cemented paste backfill: effects of mineral admixture and curing temperature," Ultrasonics, vol. 100, Article ID 105983, 2020.

[11] H. Jiao, Y. Wu, X. Chen, and Y. Yang, "Flexural toughness of basalt fibre-reinforced shotcrete and industrial-scale testing," Advances in Materials Science and Engineering, vol. 2019, Article ID 6568057, 8 pages, 2019.

[12] H.-z. Jiao, S.-f. Wang, A.-x. Wu, H.-m. Shen, and J.-d. Wang, "Cementitious property of $\mathrm{NaAlO}_{2}$-activated Ge slag as cement supplement," International Journal of Minerals, Metallurgy and Materials, vol. 26, no. 12, pp. 1594-1603, 2019.

[13] C. Qi, Q. Chen, X. Dong, Q. Zhang, and Z. Yaseen, "Pressure drops of fresh cemented paste backfills through coupled test loop experiments and machine learning techniques," Powder Technology, vol. 361, pp. 748-758, 2019.

[14] Z. Su, Q. Chen, Q. Zhang, and D. Zhang, "Recycling lead-zinc tailings for cemented paste backfill and stabilisation of excessive metal," Minerals, vol. 9, no. 11, p. 710, 2019.

[15] X. Wang, J. Liu, Q. Chen, C. Xiao, and X. Wan, "Optimal flocculating sedimentation parameters of unclassified tailings slurry," Journal of Engineering Science and Technology Review, vol. 32, no. 17, pp. 23-28, 2014.

[16] S. Li, X.-M. Wang, and Q.-L. Zhang, "Dynamic experiments on flocculation and sedimentation of argillized ultrafine tailings using fly-ash-based magnetic coagulant," Transactions of Nonferrous Metals Society of China, vol. 26, no. 7, pp. 1975-1984, 2016.

[17] S. Li and X.-M. Wang, "Fly-ash-based magnetic coagulant for rapid sedimentation of electronegative slimes and ultrafine tailings," Powder Technology, vol. 303, pp. 20-26, 2016.

[18] W. Ge, H. Li, Y. Ren, F. Zhao, and S. Song, "Flocculation of pyrite fines in aqueous suspensions with corn starch to eliminate mechanical entrainment in flotation," Minerals, vol. 5, no. 4, pp. 654-664, 2015.

[19] T. Su, T. J. Chen, Y. M. Zhang, and P. W. Hu, "Selective flocculation enhanced magnetic separation of ultrafine disseminated magnetite ores," Minerals, vol. 6, no. 3, 2016.

[20] Y. Liu, Q. Zhang, Q. Chen et al., "Utilisation of water-washing pre-treated phosphogypsum for cemented paste backfill," Minerals, vol. 9, no. 3, p. 175, 2019.

[21] Q. S. Chen, Q. L. Zhang, X. M. Wang, C. C. Xiao, and D. Xu, "Experimntal study on effect of magnetized water on flocculating sedimentation of unclassied tailings," Journal of Central South University, vol. 46, no. 11, pp. 4256-4261, 2015.

[22] Z. Gao, D. Bai, W. Sun, X. Cao, and Y. Hu, "Selective flotation of scheelite from calcite and fluorite using a collector mixture," Minerals Engineering, vol. 72, pp. 23-26, 2015.

[23] H. Han, Y. Hu, W. Sun et al., "Fatty acid flotation versus BHA flotation of tungsten minerals and their performance in flotation practice," International Journal of Mineral Processing, vol. 159, pp. 22-29, 2017.

[24] J. Wang, Z. Gao, Y. Gao, Y. Hu, and W. Sun, "Flotation separation of scheelite from calcite using mixed cationic/ anionic collectors," Minerals Engineering, vol. 98, pp. 261-263, 2016.

[25] J. Bratby, "Coagulation and flocculation," Water and Wastewater Treatment, pp. 71-77, Taylor Support Services, Melbourne, Australia, 2nd edition, 2006.

[26] S. Ahuja, Comprehensive Water Quality and Purification, Academic Press, Cambridge, MA, USA, 2014.

[27] Y. M. Wang, Treatment of the Mineral Separation Wastewater by Lime-Flocculant Sedimentation, Hunan Nonferrous Metals, Zhuzhou, China, 2005.

[28] A. L. Mackie and M. E. Walsh, "Bench-scale study of active mine water treatment using cement kiln dust (CKD) as a neutralization agent," Water Research, vol. 46, no. 2, pp. 327-334, 2012.

[29] J. Kang, C. Chen, W. Sun et al., "A significant improvement of scheelite recovery using recycled flotation wastewater treated by hydrometallurgical waste acid," Journal of Cleaner Production, vol. 151, pp. 419-426, 2017.

[30] A. Fourie, Electrokinetic Dewatering of Ultrafine Coal and Coal Tailings, Australian Centre for Geomechanics, Perth, Australia, 2008.

[31] Y. Feng, Q. Chen, Y. Zhou et al., "Modification of glass structure via $\mathrm{CaO}$ addition in granulated copper slag to enhance its pozzolanic activity," Construction and Building Materials, vol. 240, p. 117970, 2020.

[32] X. Z. Shi, H. U. Hai-Yan, D. U. Xiang-Hong, L. I. Mao-Lin, and H. Y. Wang, "Experimental study on flocculating sedimentation of tailings slurry in a vertical sand tank," Mining \& Metallurgical Engineering, vol. 27, no. 3, pp. 1-11, 2010.

[33] H. Z. Jiao, A. X. Wu, H. J. Wang, X. H. Liu, S. K. Yang, and Y. T. Xiao, "Experiment study on the focculation settlement characteristic of unclassified tailings," Journal of University of Science \& Technology, vol. 33, no. 12, pp. 1437-1441, 2011.

[34] S. Wang, Q. L. Zhang, X. M. Wang, and L. I. Shuai, "Optimal calculation mode of vertical sand silo area based on flocculating sedimentation," Journal of Northeastern University Natural Science, vol. 37, no. 10, 2016.

[35] H. Jiao, S. Wang, Y. Yang, and X. Chen, "Water recovery improvement by shearing of gravity-thickened tailings for cemented paste backfill," Journal of Cleaner Production, vol. 245, Article ID 118882, 2019.

[36] L. Besra, D. K. Sengupta, S. K. Roy, and P. Ay, "Influence of polymer adsorption and conformation on flocculation and dewatering of kaolin suspension," Separation and Purification Technology, vol. 37, no. 3, pp. 231-246, 2004.

[37] J. H. Zhe, W. H. Jiang, W. A. Xiang, J. X. Wen, and Y. Q. Wen, "Beijing. Rule and mechanism of flocculation sedimentation of unclassified tailings," Journal of University of Science \& Technology Beijing, vol. 32, no. 6, pp. 702-707, 2010.

[38] J. Hirsch and E. H. Ahrens Jr., "The separation of complex lipide mixtures by the use of silicic acid chromatography," Journal of Biological Chemistry, vol. 233, pp. 311-320, 1958.

[39] V. Lenher, "Silicic acid," Journal of the American Chemical Society, vol. 43, no. 3, pp. 391-396, 2002.

[40] D. L. Lord, A. H. Demond, and K. F. Hayes, "Effects of organic base chemistry on interfacial tension, wettability, and capillary pressure in multiphase subsurface waste systems," Transport of porous media, vol. 38, no. 1-2, pp. 79-92, 2000.

[41] H. Fang, "Study on limiting concentration of non-uniform particle flow," International Journal of Sediment Research, vol. 1, no. 11, pp. 83-88, 1996. 
[42] H. Jiao, A. Wu, H. Wang, S. Zhong, R. Ruan, and S. Yin, "The solids concentration distribution in the deep cone thickener: a pilot scale test," Korean Journal of Chemical Engineering, vol. 30, no. 2, pp. 262-268, 2013.

[43] D. Wang, Q. Zhang, Q. Chen, C. Qi, Y. Feng, and Xiao, "Temperature variation characteristics in flocculation settlement of tailings and its mechanism," International Journal of Minerals, Metallurgy and Materials, vol. 28, no. 3, pp. 1-6, 2020. 